\title{
LA OTREDAD EN LA POESÍA DE LA EXPERIENCIA: LA FIGURA FEMENINA COMO PROYECCIÓN VERBAL DE LA SOCIEDAD ESPAÑOLA POSFRANQUISTA ${ }^{1}$
}

\author{
Fernando Candón Ríos ${ }^{2}$
}

\begin{abstract}
La otredad en la poesía de la experiencia: La figura femenina como proyección verbal de la sociedad española posfranquista.

Resumen: El estudio de la representación de la mujer en la producción de los poetas de la experiencia resulta de gran interés debido al posicionamiento central de la figura femenina como eje temático en su poética. La repercusión cultural de dicho grupo es equivalente a la propia dominación hegemónica que ostenta en el campo poético español a partir de la segunda mitad de la década de los 80. Por ello, la forma de representar al personaje femenino en sus textos manifiesta indirectamente las estructuras culturales e ideológicas del contexto social, histórico y político en el que se encuadra su producción.

Palabras clave: Poesía de la experiencia, poesía española, estudios de género, feminismo, teoría de la literatura.
\end{abstract}

Otherness in the Poetry of Experience: The Female Figure as a Verbal Projection of the Post-Franco Spanish Society.

Abstract: The study of the depiction of woman in the literary work attributable to the Poets of Experience arises a great interest due to the central positioning of the female figure as a thematic axis in their poetry. The cultural repercussion of the Poets of Experience is analogue to their own hegemonic domination in the Spanish poetic field they have preserved since the second half of the 1980s. Accordingly, their way of showing the feminine figure indirectly manifests the cultural and ideological structures of the social, historical and political context in which their production is framed.

Key words: Poetry of experience, Spanish poetry, gender studies, feminism, literature theory.

El presente artículo realiza una aproximación al tratamiento de la mujer en la producción de alguno de los autores más representativos que integran el grupo de los poetas de la experiencia. El análisis no pretende presentar unos resultados concretos,

\footnotetext{
${ }^{1}$ Fecha de recepción: 10/12/2019.

Fecha de aceptación: 29/11/2019.

${ }^{2}$ Profesor Sustituto Interino, Departamento de Lenguas y Culturas Mediterráneas, Universidad de Jaén, España; $\bowtie$ fernando.candon.rios@gmail.com. Este artículo se halla vinculado al Proyecto de Investigación del Plan Estatal "Poéticas de la Transición (1973-1982)" financiado por: FEDER/Ministerio de Ciencia, Innovación y Universidades- Agencia Estatal de Investigación/ FFI2017-84759-P.
} 
sino demostrar cómo una determinada manifestación literaria resulta un producto social que refleja las estructuras culturales e ideológicas que componen una sociedad dada. Por tanto, el estudio que presentamos exhibe la manera en la que el poeta de la experiencia concibe la figura femenina, y lo pone en relación con la condición social que dispone la mujer en los años de mayor actividad del grupo -es decir, la década de los 80 y los 90-. Aunque la poesía de la experiencia disponga de representantes femeninas, el posicionamiento de la mujer como eje discursivo es un elemento característico de su poética.

El impacto social de los poetas de la experiencia está potenciado por el posicionamiento central que sus integrantes ostentan dentro de determinados campos sociales, como son aquellos que componen los culturales y los literarios. Su exposición pública -motivada por sus publicaciones con las grandes editoriales, por ganar determinados premios literarios, por colaborar con mass media, o por su actividad política- otorga una doble importancia a su poética: por un lado, representan a "la poesía oficial", ya que ellos forman parte del canon literario; por el otro, y debido al anterior punto, tienen la responsabilidad de salvaguardar el contenido y forma del mensaje lírico en tanto que son la cara visible del campo poético español. En este sentido, la importancia del contenido supera a la del continente, esto es, la expresión lírica de una época -la de la recién nacida España democrática- tiene su máximo exponente en una poética "sencilla y mundana" como es la de la experiencia. Esta poética -que se impone en una década como la de los 80 , en la que surgen numerosas corrientes y grupos que forman una vorágine literaria- manifiesta, entre otras muchas cosas, una producción creativa con roles supeditados a los géneros sexuales. La mujer se concibe como el "otro", es decir, la representación de las mujeres se manifiesta posicionándose en el centro de la motivación por la que el autor elabora el texto. Existen 
autoras femeninas entre los poetas de la experiencia, pero disponen de menor éxito y popularidad en comparación con sus congéneres masculinos. De hecho, la única mujer seleccionada entre los poetas recogidos en la antología Poesía de la experiencia (Iravedra 2007) es Ángeles Mora.

La sociedad expresa su ideología a través del arte, por lo que la poesía se configura como una manifestación de la cultura a la que pertenece su autor. Por tanto, la expresión lírica, como objeto verbal estético, dispone de un sistema de significación correspondido por un significante, donde este último predomina sobre el significado. En relación con lo expuesto, el sociólogo francés Pierre Bourdieu comenta en esta línea lo siguiente:

El principio de la acción histórica, ya sea la del artista, la del científico o la del gobernante, como ya sea la del obrero o del funcionario subalterno, no es un sujeto que enfrente a la sociedad como a un objeto constituido en la exterioridad. [...] El cuerpo está en el mundo social, pero el mundo social está en el cuerpo. Y la incorporación de lo social que lleva a cabo el aprendizaje es el fundamento de la presencia en el mundo social que supone la acción socialmente ejecutada con éxito y la experiencia corriente de este mundo como evidente. (Bourdieu 2002: 40-41)

A pesar de ello, el significado sigue teniendo un valor fundamental para estudiar las relaciones del autor con su contexto histórico y social. Así, la dominación simbólica del hombre sobre la mujer encuentra un punto de proyección cultural en el género lírico. El caso que tratamos, la poesía de la experiencia, expone al personaje femenino como eje central sobre el que se desarrolla el texto. Este centralismo argumental no es nuevo, la mujer como tema sobre el que se construye el objeto verbal estético es casi tan antiguo como la propia existencia de la lírica, la diferencia se encuentra en la contextualización de la propia poesía de la experiencia, producida en un momento en el que socialmente existen agentes sociales y movimientos de empoderamiento feministas. 
Esta paradoja cultural puede encontrar su explicación en las acusaciones que tachan a los poetas de la experiencia de producir una poética afín al sistema capitalista, al prescindir de cualquier elemento que se posicione contra éste (Iravedra 2006). Bourdieu explica que los agentes de los campos sociales elaboran estrategias para "adaptarse" al "juego" interno con la intención de dominar el campo específico. Por tanto, el desarrollo de los parámetros por el que evoluciona las características y movimientos de la poesía de la experiencia -a pesar de los origines y reivindicaciones- tiene sentido a la luz de un análisis que tenga como intención encontrar las razones de la hegemonía del grupo:

El sentido del juego no es infalible; está desigualmente repartido en una sociedad como en un equipo. (...) Pero esta libertad de invención, de improvisación, que permite producir la infinidad de jugada hechas posibles por el juego (como el ajedrez) tiene los mismos límites que el juego. Las estrategias adaptadas tratándose de jugar al juego. (Bourdieu 2007:70)

Para entender el porqué una corriente como la de la experiencia, que surge en el advenimiento democrático, proyecta en su poética la mujer como una figura aún anclada a un estereotipo basado en convenciones culturales de tiempos pasados, resulta necesario entender la naturaleza de la Transición española y su benevolencia con la herencia franquista. Esto se debe a que, tras el fin de la dictadura, en España se vive un momento de apertura cultural y social que desarrolla con gran intensidad durante los primeros años de la década de los 80 . El pensamiento posmoderno, que se expande ajeno al territorio español debido a las restricciones impuestas por el gobierno franquista hasta el boom económico de la década de los 60, establece ahora sus estructuras ideológicas y sus nuevas prácticas de consumo. Debido a ello la sociedad española abandona la actitud subversiva de los últimos años del franquismo para instalarse en la tranquilidad avenida con la democracia. El habitus de los campus sociales no se 
transforma con llegada de las primeras elecciones generales, sino que se adapta. De esta manera, la mujer - que durante la dictadura deviene en una figura subyacente, delimitada socialmente y señalada como "el otro" por su género- puede equipararse al hombre en derechos legales, pero su posicionamiento social se mantiene alejado de la situación masculina.

En este sentido, aludiendo a los presupuestos teóricos que dan lugar a la célebre teoría del reflejo de Georg Lukács (1963), podemos definir el arte como un objeto estético que manifiesta las relaciones entre los componentes de una determinada sociedad dentro un modo de producción dado. Por ello, con la llegada de los años ochenta, de la otra sentimentalidad y el éxito que posteriormente da pie a la hegemonía de los poetas de la experiencia, aparece una producción poética que puede ser entendida a varios niveles: $1^{\circ}$ Desde la construcción de un discurso acorde a los nuevos tiempos democráticos, es decir, una poética que alude a las vivencias en la vida urbana, en la que la ciudad se dispone como uno de los ejes discursivos; $2^{\circ}$ La poesía de la experiencia propone un relato verosímil, cargado de elementos expresivos que forman la configuración de la mímesis; $3^{\circ}$ Debido al escaso número de autoras femeninas reconocidas en la antología de referencia, es decir, la de Araceli Iravedra (2007), la figura de la mujer se proyecta como la del "otro". Esta tendencia no resulta exclusiva de esta corriente, sino que corresponde a un "modus operandi" de las antologías poéticas del último tercio del siglo XX, ya que la presencia de autores femeninos entre sus antalogados era mínima o ninguna:

Finalmente, la antología cúspide de lo que fue la poesía figurativa de la generación de los 80 , y que recoge a los autores que se encuadran dentro de la rama de la experiencia, es la realizada por Araceli Iravedra en el 2007, titulada Poesía de la Experiencia. El resultado no es mucho más alentador que los anteriores: de los diez autores catalogados, nueve son hombres y una es mujer (10\%). (Candón 2017: 91) 
Con una poética con claro sesgo masculino, la poesía de la experiencia ve en el género femenino un late motiv constante. En su producción la mujer se sitúa como protagonista indirecta o directa de la causa del poema. La construcción lírica del texto sustenta sus bases en varios ejes culturales heredados directamente de la visión femenina de los tiempos de la dictadura.

Entonces, el texto lírico como objeto verbal estético asume a la mujer como elemento central. La cadencia temática del poema suele tender hacia el enfoque amoroso (positivo o negativo), aunque la mujer también aparece representada como un personaje anónimo en clara alusión a la femme fatale. La poesía de la experiencia construye su imaginario a través del relato de lo cotidiano, de la urbe, de la noche, de los bares y los hoteles. Su literalidad se forma a través del monólogo dramático y la máscara autobiográfica. La naturaleza de la producción poética de la experiencia no está exenta de críticas. Las más comunes acusan a estos poetas, como recoge Iravedra (2007: 121) en su antología canónica, de "narcisistas, indiferentistas y totalitarios":

Narcisismo, porque reconocen en el protagonista de la poesía de la experiencia a un sujeto que, lejos de pensarse en su constitución comunitaria, se afirma como sujeto ensimismado y hace gala de una privacidad autosuficiente, de espaldas al espacio de lo público y a toda responsabilización ante la comunidad. Indiferentismo, porque los axiomas idealistas y esencialistas que a su juicio la sustentan determinan que la realidad no se perciba como construcción histórica sino como ente abstracto e inmutable, lo cual conduce a una ética de la sumisión ante lo dado que favorece el asentamiento de la normalidad capitalista, y aleja a la poesía de la experiencia de cualquier "modelo cultural transformador del mundo". Totalitarismo, en fin, porque la ideología de la aceptación (solidaria con el discurso político institucional) y, sobre todo, la "normalización realista" de lo ya dado como si fuera inmutable, tienen que derivar en la formulación de mensajes totalitarios. 
Vemos como, por ejemplo, en la producción poética de uno de los autores principales de la experiencia, como es García Montero, la mujer se erige baluarte del mensaje. El posicionamiento femenino tiene un carácter central sobre el que articula todo el eje verbal, provocando que el yo poético se sitúe frente al hipotético "otro". Si tomamos por ejemplo el texto "El lugar del crimen" (1989: 19) podemos apreciar los siguientes versos:

\author{
Más allá de la sombra \\ te delatan tus ojos, \\ $\mathrm{y}$ te adivino tersa, \\ como un mapa extendido \\ de asombro y de deseo. \\ Date por muerta \\ amor, \\ es un atraco. \\ Tus labios o la vida
}

El texto describe el diálogo de dos amantes que se encuentran en un momento concreto en que el público lector puede presuponer que existe una tensión sexual dispuesta a resolverse de manera inmediata. El yo poético proyecta cierta violencia de carácter simbólico sobre el sujeto pasivo que es la amante. La mujer aparece como ese "otro" que responde ante la iniciativa del hombre, que ejerce sobre su figura la fuerza de la dirección de los acontecimientos. La propuesta final que se le ofrece a la amante -la posibilidad de elegir entre "sus labios" o "la vida"- no resulta más que un juego retórico, ya que, según se desprende del poema, el yo poético tiene decidido el final de la historia.

Si la mujer puede proyectarse como un objeto de deseo pasivo, también tiene de forma recurrente una función secundaria, que estaría materializada dentro del texto en 
forma de personaje principal supeditado al yo poético. Así, tomando otro ejemplo, vemos cómo en el poema "Tiempo muerto" (1998), Benjamín Prado construye la imagen de una pareja sobre el lecho común, donde ella es una figura muda que queda anulada por el sueño en los primeros versos, mientras que la voz poética no detiene su dialogo: "Ha sido un día raro. Estás tumbada / junto a mí. / Casi puedo escuchar la marea / de la sangre en tu piel / y el deseo que llena tus manos de leones. / Luego, apagas la luz" (1-6). Una vez más, el hombre siente la pasión en el cuerpo femenino, sin que éste emita ningún tipo de expresión en ese sentido ni su personaje exclame nada. El poema continúa más adelante en estos términos:

Tú sigues a mi lado.

Tu corazón golpea dentro de la mujer

dormida, igual que un perro ladrándole a las tumbas. Me pregunto, después de tantas cosas, cuando cada hora quema su selva entre mis manos, me pregunto qué es lo que sé de ti; si tal vez, como dice Marianne Moore, lo importante de lo que vemos es lo que no vemos. (34-44)

Apreciamos cómo Prado dibuja la imagen verbal de un personaje femenino inerte, cuyo corazón ejecuta una función fútil frente a una consciencia que lo ignora, no sabemos si por su estado somnoliento o si esto sucede de forma voluntaria, ya el resto del texto parece indicar que existe cierta confrontación reciente entre ambos.

Si con García Montero encontramos un ejemplo de la mujer como objeto de deseo indefenso y con Prado como una figura pasiva y muda, veamos a continuación al personaje femenino ausente pero deseado. Es decir, como obsesión del yo poético que basa su existencia (y el sentido del texto) en el "otro", que es un personaje femenino 
indefinido. Si acudimos al poema "La condición del personaje" (1992), del poeta granadino Álvaro Salvador, leemos lo siguiente:

Te he buscado por bares y por días sin saber encontrarte.

Recorrí las callejas de tu barrio -donde vivo también, de vez en cuandoy he dejado los rastros de mi paso por si acaso los vieras, telegramas que cortejan tu nombre en las aceras.

Te he buscado por noches, entre copas duras seguramente y excesivas, esperando alcanzar la madrugada de tus ojos cachorros: y encontrarte.

He pensado en llegarme hasta tu calle, preguntar por tu puerta y proponerte una cita, unas flores, un poema (1-14)

El "otro" se configura como una hipótesis ausente. El yo poético la desea, pero ese deseo no se sacia ya que la búsqueda resulta en vano. El relato de esta ausencia, de esta mujer con ojos de "cachorro", que vive en el mismo barrio que la voz poética, se proyecta a través de dos tópicos: el poeta taciturno y solitario, y la chica que no corresponde el amor procesado por este. Salvador, al jugar con el título del poema y con los personajes clásicos en la producción poética de la experiencia, expone la posición femenina en el texto y la descubre como una figura carente de respuesta, ausente aunque sea citada en el texto, la presencia femenina suele ser meramente referencial- y cuya existencia dentro del poema tiene como objetivo posicionarse como eje central discursivo.

Podríamos argumentar que en la poesía de la experiencia la mujer se desvela como "mito" y el poeta como un "sacerdote" que refiere su producción literaria a la consagración de una tradición que se basa en un dogma principal: El poeta existe porque 
"el otro" (en este caso la mujer) lo provoca. Es decir, la experiencia surge de los acontecimientos cotidianos que, referidos a la corriente que nos concierne, se basan en recuerdos -a menudos nocturnos y urbanos- que causan dolor y/o melancolía en la voz poética.

En el poema "El mujeriego" (1990)' Vicente Gallego construye el texto lírico a través de un personaje obsesionado con las mujeres. Así, apreciamos los siguientes versos:

He amado a las mujeres, todavía las amo, y sufro mucho al verlas alejarse, espléndidas y ajenas, con sus hijos de la mano, o aún con uniforme, casi niñas -la nuca entre sudada y el olor a colonia tras los juegos-, $o$ adolescentes casi, en esa edad en que duermen inquietas si es verano.

Y todas con olores que nos hacen soñar, en su belleza crueles, pues sólo esos olores, extraños y envolventes, al cabo han de dejar, si pasan cerca, como un camino abierto en nuestras vidas. Pero fui terco en el amor de algunas, y es difícil así frecuentarlas a todas.

He amado a las mujeres, y por ellas sospecho que quisiera perderme, si tuviera dinero, y ayudaran un poco. (23-40)

Nos encontramos ante una intensa obsesión del yo poético por la figura de la mujer, que resulta cuanto menos enfermiza, ya que no discrimina entre niñas y adultas, llegando a rozar lo esperpéntico al describir a las adolescentes durmiendo en verano. Una vez más, el poeta elabora un discurso donde el "otro" es un sujeto pasivo, ausente y carente de emociones, que, además, rechaza a la voz poética por la "torpeza" de esta y por el carácter de ellas. 
Podemos concluir tratando el concepto de ficción autobiográfica que abanderan los poetas de la experiencia. La ficción no deja de ser una parte insertada dentro de las estructuras que forman la realidad. En estos términos, Jesús G. Maestro (2014: 380) afirma lo siguiente:

Se confirma que la ficción forma parte necesariamente de la realidad, porque Realidad y Ficción no son conceptos dialécticos, sino conceptos conjugados. La ficción es interpretable -y posible- porque existe la realidad, en cuyas estructuras (formas y materias) toda ficción está insertada, como construcción real y como realidad constituyente. Por esa razón la ficción literaria no es una suerte de réplica de la realidad, verosímilmente expresada o compuesta, según umbrales de aproximación.

Por lo tanto, toda ficción tiene una base compuesta por las estructuras que conforman la realidad. Esta idea nos vuelve a situar dentro de la perspectiva de Lukács. La exhibición manifiesta, de parte de un gran número de poetas de la experiencia, de una escritura que ofrece al lector la imagen de la mujer como una suerte de horizonte de sucesos hacia el que se dirige inexorablemente el texto que configura el significado del objeto verbal estético. Esta configuración sitúa al personaje femenino como objeto de deseo o bien como elemento disruptivo en la vida rutinaria del yo poético. Es decir, lo femenino se concibe como algo ajeno a lo normal, algo que se traduce en una otredad muy marcada. Pero este "otro" no viene formado desde la poesía de la experiencia, este otro es el reflejo de una sociedad española que aún no ha superado muchas barreras culturales heredadas directamente del franquismo, que todavía no es capaz de concebir una perspectiva social no basada en los géneros sexuales $\mathrm{y}$, sobre todo, que sigue proyectando en la figura femenina un carácter pasivo. A esto hay que añadirle que, aludiendo a la terminología de Roland Barthes, la poética de la experiencia se enmarca en esa categoría literaria que el teórico francés nominó como "legible", es decir, aquel 
texto que condena al lector a enfrentarse al texto de manera ociosa, dejándole solo dos alternativas: aceptarlo o rechazarlo. Por tanto, la poesía de la experiencia no rebate las estructuras sociales, sino que las muestra tal y como son. Así, podemos concluir afirmando que la producción de los poetas de la experiencia resulta un producto social representativo de la cultura occidental capitalista del siglo XX.

\section{Referencias bibliográficas}

Bourdieu, Pierre. 1995. Las reglas del arte. Génesis y estructura del campo literario. Barcelona: Anagrama, 1992. 2002. Lección sobre la lección. Barcelona: Anagrama 2007 [1987]. "De las reglas a las estrategias". Cosas Dichas. Barcelona: Gedisa: 67-82.

Candón Ríos, Fernando. 2017. "Silencio y marginalidad. Apuntes sociológicos sobre la ausencia de la mujer en las grandes antologías españolas de poesía del último tercio del siglo XX”. Confluenze. Rivista di Studi Iberoamericani, 9 (2): 86-97.

Gallego, Vicente. 1990. Los ojos del extraño. Madrid: Visor.

García Montero, Luis, y Álvaro Salvador. 1989. Tristia. Madrid: Hiperion, 1982.

Iravedra, Araceli. 2006. “"Radicales, marginales y heterodoxos” en la última poesía española (contra la "poesía de la experiencia")". Anales de la literatura española contemporánea, ALEC, 31 (1): 119-38.

2007. Poesía de la experiencia. Madrid: Visor.

Lukács, Georg. 1966. Estética I. Barcelona: Grijalbo, 1963.

Maestro, Jesús G. 2014. Contra las Musas de la Ira: El Materialismo Filosófico como Teoría de la Literatura. Oviedo: Pentalfa.

Prado, Benjamín. 1998. Todos nosotros. Madrid: Hiperión.

Salvador, Álvaro. 1992. La condición del personaje. Granada: Caja de Ahorros de Granada. 